\title{
A experiência das disciplinas de formação docente em ensino de Física no MNPEF-UEPG: proposta pedagógica, reflexões e ações
}

\section{The experience of the disciplines of teachers education in Physics teaching in the MNPEF-UEPG: pedagogical proposal, reflections and actions}

\author{
Silvio Luiz Rutz da Silva* \\ AndréMaurício Brinatti* \\ André Vitor Chaves de Andrade *** $^{* *}$
}

\section{Resumo}

Neste trabalho, relatamos uma experiência de planejamento de atividades pedagógicas, na qual o modelo de ensino empregado foi a construção do conhecimento a partir das experiências pessoais dos professores-discentes, de modo a conduzi-los a uma reflexão sobre sua história de formação profissional. O método empregado, fundamentado nas teorias de aprendizagem, foi pautado em uma abordagem humanista com elementos cognitivistas, sendo que as metodologias empregadas tiveram variações em função dos objetivos propostos para cada um dos conteúdos abordados. Esse processo de ensino-aprendizagem conduz à formação de docentes-pesquisadores como resultado de uma atividade reflexiva, crítica e inovadora, aplicada diretamente à atuação profissional do docente, na produção de conhecimento diretamente associado à prospecção de problemas e soluções para o ensino-aprendizagem dos conhecimentos em Física. A intenção é oferecer referências de propostas de ensino de Física coerentes com as estruturas de pensamento exigidas pela ciência e pela tecnologia, pelo exemplo de suas inserções na realidade educacional, ao mesmo tempo que mostrem como se pode dar tratamento adequado à interdependência de conteúdos para a formação de visão das interconexões dos conteúdos da Física.

Palavras-chave: Ensino. Física. Metodologia. Planejamento. Trabalho docente.

Recebido em 19/10/2017 - Aprovado em 23/01/2018

http://dx.doi.org/10.5335/rep.v25i2.8168

Doutor em Ciências dos Materiais pela Universidade Federal do Rio Grande do Sul. Docente permanente do Programa do Pós-Graduação em Ensino de Física do Mestrado Nacional Profissional em Ensino de Física (MNPEF), Polo Universidade Estadual de Ponta Grossa (UEPG), e do Programa de Pós-Graduação em Ensino de Ciências e Educação Matemática (PPGECEM-UEPG). Professor de Física e assessor da Pró-Reitoria de Extensão e Assuntos Culturais da UEPG. E-mail: rutz@uepg.br

** Doutor em Ciências (área de concentração Física Aplicada) pelo Instituto de Física de São Carlos da Universidade de São Paulo (IFSC-USP). Docente permanente do Programa de Pós-Graduação em Ensino de Física do Mestrado Nacional Profissional em Ensino de Física (MNPEF), Polo UEPG, do Programa de Pós-Graduação em Ensino de Ciências e Educação Matemática (PPGECEM-UEPG) e do Programa de Pós-Graduação em Ciências (PPGCiências-UEPG). Professor de Física na UEPG. E-mail: brinatti@uepg.br

*** Doutor em Química pela Universidade Estadual Paulista Júlio de Mesquita Filho (Unesp-Araraquara). Docente permanente do Programa de Pós-Graduação em Ensino de Física do Mestrado Nacional Profissional em Ensino de Física (MNPEF), Polo UEPG, e do Programa de Pós-Graduação em Ciências (PPGCiências-UEPG). Professor de Física na Universidade Estadual de Ponta Grossa. E-mail: avca@uepg.br 


\section{Abstract}

In this work, it relates an experience of planning pedagogical activities, in which it is the teaching model used for a construction known from the e-mail systems of the teacher-students to lead them to reflect on their history of professional formation. The method used, based on the theories of learning, was based on a humanist approach with cognitive elements and the methodologies used had variations according to the objectives proposed for each of the contents addressed. This teaching-learning process leads to the formation of teacher-researchers as a result of a reflexive, critical and innovative activity applied directly to the professional performance of the teacher, in the production of knowledge directly associated with the prospect of problems and solutions for the teaching-learning of the teachers knowledge in Physics. The intention is to offer references of proposals of Physics Teaching coherent with the structures of thought required by science and technology, by the example of its insertions in the educational reality, at the same time as they show how it is possible to give adequate treatment to the interdependence of contents for the formation of vision of the interconnections of the contents of Physics.

Keywords: Teaching. Physics. Methodology. Planning. Teaching work.

\section{Introdução}

Aperfeiçoar a formação profissional dos professores, em especial da educação básica, é uma medida de suma importância para melhorar a qualidade da educação. A valorização e a qualificação dos professores são consideradas fundamentais para a melhoria da qualidade da educação, assumida pelos Estados-Membros da Organização das Nações Unidas para a Educação, a Ciência e a Cultura (UNESCO) em dois dos seis objetivos do Marco de Ação de Dacar 2000 da Declaração sobre Educação para Todos (UNESCO, 2017).

Para melhorar a qualidade da educação, conforme registra o relatório da UNESCO elaborado pela Comissão Internacional sobre a Educação para o século XXI:

[...] é preciso, antes de mais nada, melhorar o recrutamento, a formação, o estatuto social e as condições de trabalho dos professores pois estes só poderão responder ao que deles se espera se possuírem os conhecimentos e as competências, as qualidades pessoais, as possibilidades profissionais e a motivação requeridas (UNESCO, 2017).

Neste texto, será dado enfoque à formação do professor, em especial do professor de Física, sendo que se julga importante levar em consideração o que envolve o trabalho docente, que vai muito além das atividades desenvolvidas nas classes nas quais o professor ministra suas aulas.

Muitos pesquisadores na área de formação docente têm dedicado seus estudos nesse campo a avaliações e proposições de elementos que devem constar tanto na formação inicial quanto na continuada. Um exemplo é o trabalho de Gatti e Barreto (2009), intitulado Professores no Brasil: impasses e desafios, desenvolvido para a UNESCO, no qual os autores fazem um balanço da formação de professores da 
educação básica, com vistas à melhoria da qualidade da educação e à valorização da profissão docente. Segundo Gatti e Barreto, o objetivo do estudo foi: "[...] examinar aspectos ligados à formação e à profissão docente no ensino básico brasileiro, questões críticas no cenário das políticas contemporâneas, particularmente ligadas ao grande desafio da melhoria da qualidade da educação para todos" (2009, p. 1).

O trabalho de Gatti e Barreto (2009) abordou a docência no mundo do trabalho e suas características, o perfil dos docentes em exercício, a legislação sobre formação de professores e suas decorrências, a formação inicial em cursos presenciais e a distância, o currículo nas licenciaturas e o perfil dos licenciandos, os modelos especiais de formação de professores, a formação continuada e seus problemas, a carreira, os salários e suas implicações. Tais aspectos, segundo os autores, são importantes por influenciarem fortemente a qualidade educacional.

A partir de tais constatações, surge a seguinte questão: quais são os elementos que devem constar na formação docente no que diz respeito à organização do trabalho docente no espaço escolar? Tal questão envolve: gestão (de pessoas e de ações indicadas ou estabelecidas em leis e diretrizes), demandas sociais e econômicas, de planejamento, de execução desses planejamentos, de avaliação desses planejamentos, além da ação efetiva de docência na relação ensino-aprendizagem.

\section{Os programas de formação docente}

A Lei no 11.502, de julho de 2007 (BRASIL, 2007), atribui à Coordenação de Aperfeiçoamento de Pessoal de Nível Superior (Capes) a responsabilidade pela formação de professores da educação básica. O objetivo é assegurar a qualidade da formação dos professores que atuarão ou que já estejam em exercício nas escolas públicas, além de integrar a educação básica e a educação superior, visando à qualidade do ensino público. A Política Nacional de Formação de Professores tem como objetivo expandir a oferta e melhorar a qualidade nos cursos de formação dos docentes (BRASIL, 2017; CAPES, 2017a).

Em relação à formação de professores da educação básica, a Diretoria de Formação de Professores da Educação Básica (DEB) atua em duas linhas de ação: na indução à formação inicial de professores para a educação básica, organizando e apoiando a oferta de cursos de licenciatura presenciais especiais, por meio do Plano Nacional de Formação de Professores da Educação Básica (Parfor); e no fomento a projetos de estudos, pesquisas e inovação, desenvolvendo um conjunto articulado de programas voltados para a valorização do magistério.

O conjunto dos programas insere-se em uma matriz educacional que articula três vertentes: formação de qualidade; integração entre pós-graduação, formação 
de professores e escola básica; e produção de conhecimento. Na base de cada ação da DEB, está o compromisso da Capes de valorizar o magistério da educação básica (CAPES, 2017b).

Os programas mantêm um eixo comum, que é a formação de qualidade, em um processo intencional, articulado e capaz de se retroalimentar, gerando um movimento progressivo de aperfeiçoamento da formação docente. Nesse contexto, os principais programas são: Programa Institucional de Bolsa de Iniciação à Docência (Pibid); Programa de Consolidação das Licenciaturas - Prodocência; Observatório da educação (Obeduc); Parfor; Programa Novos Talentos; Programa de Apoio a Laboratórios Interdisciplinares de Formação de Educadores (Life) (CAPES, 2017a).

Tais programas têm por foco a formação inicial dos professores. No âmbito da formação continuada, entre as opções oferecidas pelas universidades brasileiras, destaca-se o mestrado profissional. Além de proporcionar livre-docência em qualquer instituição de ensino superior do país, o mestrado profissional é direcionado aos que pretendem adquirir alto nível de qualificação profissional, tendo por foco sua própria atuação.

\section{Mestrados profissionais}

De acordo com a Capes, em 1999, ano de criação da modalidade, havia a oferta de apenas quatro cursos de mestrado profissional. O salto se deu a partir de 2007, com a oferta de 184 opções, sendo que, atualmente, existem 786 opções de cursos de mestrado profissional distribuídas em diversas regiões do Brasil (CAPES, 2017b, 2018).

Promovido em 2015, pela Universidade de Campinas (Unicamp), o Fórum Universidade Pública e o Ensino de Ciências: investigando a experiência dos mestrados profissionais para a qualificação dos professores debateu o papel do mestrado profissional na formação docente (UNICAMP, 2015). Estiveram reunidos, para debater suas vivências, pesquisadores, coordenadores de cursos, mestres e mestrandos dessa modalidade de pós-graduação stricto sensu. Entre os palestrantes, estiveram profissionais de órgãos governamentais e sociedades científicas, tais como a Sociedade Brasileira de Física (SBF), o Instituto Nacional de Matemática Pura e Aplicada (Impa), a Sociedade Brasileira de Química (SBQ), a Academia Brasileira de Ciências (ABC) e a Sociedade Brasileira para o Progresso da Ciência (SBPC), e representantes do Mato Grosso, Espírito Santo, Rio de Janeiro, São Paulo e Distrito Federal.

Como conclusão, os participantes do fórum ressaltaram que o mestrado profissional consiste em uma importante ferramenta para o aprimoramento dos professores da educação básica no Brasil. Outro ponto considerado importante foi a des- 
vinculação entre a pesquisa em educação e os problemas reais da educação pública (UNICAMP, 2015). Os participantes do fórum elencaram como desafios a serem superados pelos mestrados profissionais: a interiorização, já que muitos alunos precisam percorrer grandes distâncias para frequentar as aulas presenciais; e as condições de trabalho desses mestres ao retornarem para a sala de aula, quando se depararam com condições inapropriadas de trabalho para sustentar a aplicação daquele material desenvolvido durante o seu mestrado (UNICAMP, 2015).

Nessa perspectiva, desde 2013, o Programa Nacional de Mestrado Profissional em Ensino de Física (MNPEF) é voltado a professores de ensino médio e fundamental com ênfase principal em aspectos de conteúdos na área de Física. O MNPEF é uma iniciativa da SBF, com o objetivo de coordenar diferentes capacidades apresentadas por diversas instituições de ensino superior (IES), distribuídas em todas as regiões do país (SBF, 2018).

\section{Mestrado nacional profissional em ensino de Física}

O objetivo do MNPEF é capacitar, em nível de mestrado, uma fração muito grande de professores da educação básica quanto ao domínio de conteúdos de Física e de técnicas atuais de ensino para aplicação em sala de aula, como estratégias que utilizam recursos de mídia eletrônica, recursos tecnológicos e/ou computacionais para motivação, informação, experimentação e demonstração de diferentes fenômenos físicos, com abrangência nacional e universal. Para tanto, o programa está organizado em polos regionais, hospedados por alguma IES, na qual ocorrerem as orientações das dissertações e são ministradas as disciplinas do currículo (SBF, 2018).

As linhas de pesquisa e desenvolvimento do MNPEF estão organizadas de forma a classificar as dissertações ou materiais instrucionais produzidos pelos alunos como requisito para a obtenção do título de mestre. Identificam-se, preliminarmente, três importantes vertentes (SBF, 2018):

a) Física no ensino fundamental: desenvolvimento de produtos e formas de abordagem visando conteúdos de Física adequados a estudantes do ensino fundamental, de forma integrada com outras disciplinas;

b) Física no ensino médio: atualização do currículo de Física para o ensino médio, de modo a contemplar resultados e teorias da Física contemporânea, visando uma compreensão adequada das mudanças que esses conhecimentos provocaram e irão provocar na vida dos cidadãos;

c) Processos de ensino e aprendizagem e tecnologias de informação e comunicação no ensino de Física - formação de professores de Física em nível de 
mestrado: desenvolvimento de produtos e processos de ensino e aprendizagem que utilizem tecnologias de informação e comunicação, tais como aplicativos para computadores, mídia para tablets, plataforma para simulação e modelagem computacionais, aquisição automática de dados, dispositivos móveis de comunicação e redes sociais.

Vale ressaltar que o MNPEF exige a elaboração de um produto educacional, que busque alternativas ou resolva problemas relacionados às práticas cotidianas dos mestrandos. Assim, a dissertação se torna uma investigação sobre a aplicação desse produto.

No desenvolvimento das propostas de formação do MNPEF, estar em serviço é pré-requisito, uma vez que essa modalidade de formação visa à realização de pesquisas aplicadas, buscando a resolução de problemas nacionais e locais, trazendo, portanto, especificidades e particularidades. A ênfase principal está em instrumentalizar o professor-discente, isto é, o professor em exercício e aluno do mestrado profissional, para a atividade reflexiva, crítica e inovadora, aplicada diretamente à sua atuação profissional como docente, na produção de conhecimento diretamente associado à prospecção de problemas e soluções para o processo de ensino-aprendizagem dos conhecimentos em Física, apresentando estudos e pesquisas com suporte teórico, para que os profissionais da educação tenham condições de inovar sua prática em termos de compreensão e aplicação da ciência.

Nesse processo, um dos elementos essenciais de reflexão é a compreensão da abrangência do trabalho docente e de como esse está inserido na realidade escolar. Na sequência, apresentam-se alguns elementos desse contexto.

\section{A organização do trabalho docente}

A organização do trabalho docente consiste em refletir sobre aspectos da organização do trabalho pedagógico da escola, com o objetivo de interpretar e destacar a importância da participação de professores e coordenadores pedagógicos nessa organização. Ressalta-se, ainda, o significado do planejamento da organização da vida escolar nos termos educacional, social e político (LIMA et al., 2014).

$\mathrm{Na}$ construção do trabalho pedagógico, é importante a compreensão de quais são os fundamentos e os instrumentos que norteiam o processo. Os fundamentos requeridos para a organização do trabalho docente estão relacionados a intencionalidade, participação coletiva, planejamento e respeito aos contratos sociais estabelecidos. É nesse contexto que se configura o papel do professor como sujeito ativo na organização do trabalho pedagógico escolar. Como instrumentos, consideramos: o Projeto Político-Pedagógico (PPP), a Proposta Pedagógica Curricular (PPC), o 
Plano de Trabalho Docente (PTD), o Regimento Escolar e Estatuto(s). Além desses, devem ser considerados os sujeitos da prática educativa: professores, coordenadores pedagógicos, pedagogos, funcionários, pais e estudantes. Os fundamentos englobam dois grandes grupos: os fundamentos legais (leis, decretos, portarias e pareceres) e os fundamentos filosóficos, sociológicos, políticos, antropológicos e pedagógicos (LIMA et al., 2014).

O PPP reflete o impacto da legislação na organização do trabalho coletivo escolar, representa a intencionalidade educativa da escola; sendo, portanto, o registro dessas reflexões coletivas a respeito do cotidiano e das relações presentes no ambiente escolar. Ele deve traduzir a proposta educativa construída pela comunidade escolar no exercício de sua autonomia, com base no diagnóstico da realidade resultante da análise dos problemas e das possibilidades.

Nesse contexto, pode-se dizer que o trabalho docente vai muito além das atividades que ocorrem em sala de aula, pois envolve reflexão, organização e sistematização do trabalho pedagógico nos espaços escolares, que resultarão na forma específica de como o docente interage com a disciplina, ou seja, como distribui o tempo e organiza as relações no espaço escolar, enfatizando as características e as condições operacionais para o seu trabalho. Todo esse processo consiste em planejar.

O planejamento deve alcançar não só que se façam bem as coisas (eficiência), mas que se façam as coisas que realmente importa fazer, porque são socialmente desejáveis (eficácia). O planejamento é um processo educativo. Na elaboração do planejamento, há três perguntas básicas (LIMA et al., 2014): o que queremos alcançar? A que distância estamos daquilo que queremos alcançar? O que faremos concretamente (num prazo predeterminado) para diminuir essa distância?

Planejar é responder a essas questões, e, nesse processo, as etapas a serem executadas são (LIMA et al., 2014):

a) elaborar - decidir que tipo de ação educacional é necessária; verificar a que distância se está desse tipo de ação e até que ponto se está contribuindo para o resultado final que se pretende; e propor uma série orgânica de ações para diminuir essa distância e para contribuir mais para o resultado final estabelecido;

b) executar: agir em conformidade com o que foi proposto;

c) avaliar: revisar, sempre, cada um desses momentos e cada uma das ações, bem como cada um dos documentos deles derivados.

Nesse processo de organização do trabalho docente, no qual o planejamento é peça chave, a efetiva compreensão de alguns conceitos é fundamental. A seguir, será feita uma breve descrição dos conceitos mais relevantes nessa tarefa. Nesse 
relato, apresenta-se o trabalho desenvolvido em três disciplinas do curso MNPEF, polo 35, da UEPG.

\section{A organização de uma sequência didática no MNPEF-UEPG}

Neste trabalho, relata-se uma experiência de planejamento de atividades pedagógicas, para a qual o modelo empregado foi a construção do conhecimento a partir das experiências pessoais dos professores-discentes, de modo a conduzi-los a uma reflexão sobre sua história de formação profissional. O método empregado foi pautado em uma abordagem humanista com elementos cognitivistas, e as metodologias empregadas tiveram variações em função dos objetivos propostos para cada um dos conteúdos. Tanto o método quanto as metodologias empregadas foram baseados nas teorias de aprendizagem.

O método, a metodologia, as técnicas, as estratégias e os recursos empregados nas três disciplinas no MNPEF-UEPG conduziram as atividades propostas pelos professores, individualmente, na perspectiva de se estabelecer reflexões sobre: 0 que ensinamos? a construção do conhecimento - comunicação do conhecimento - o que significa entender? - a colaboração na aula - o planejamento de uma unidade didática.

As atividades desenvolvidas tiveram por objetivo estabelecer uma rotina para o planejamento didático a partir de uma concepção fundamentada nas teorias de aprendizagem, considerando as diversidades de experiências de ensino e de aprendizagem com integração de tecnologias por parte dos alunos da educação básica. Buscou-se oportunizar aos professores-discentes o reconhecimento dos processos cognitivos da construção do conhecimento, com enfoque nos conteúdos abordados nas três disciplinas, em um processo de análise reflexiva continuada e da consequente reconstrução das atividades.

As aulas envolveram leituras e discussões sobre o que ensinamos, isto é, sobre o conhecimento social e de conteúdo, com o propósito de analisar como esses aspectos se manifestam na prática profissional dos professores-discentes. O processo de construção do conhecimento, que passa pela compreensão de como o indivíduo aprende dentro do contexto do conhecimento historicamente e socialmente construído, teve por propósito o reconhecimento dos elementos-chave para a comunicação efetiva em uma aula e a análise dos processos de avaliação a partir da compreensão de como os alunos entendem os conteúdos A maioria das atividades desenvolvidas teve caráter coletivo, com o objetivo de conduzir os alunos à compreensão do potencial do trabalho cooperativo e colaborativo durante a aula. $\mathrm{O}$ elemento catalizador de todo o processo foi o planejamento de uma unidade didática e de uma sequência 
de aulas de modo a reconhecer os elementos constitutivos de uma unidade didática e de uma aula fundamentados nas teorias de aprendizagem.

As disciplinas nas quais as atividades foram desenvolvidas foram: Processos e Sequências de Ensino e Aprendizagem em Física no Ensino Médio (PSEAFEM); Fundamentos Teóricos em Ensino e Aprendizagem (FTEA); e Atividades Experimentais para os Ensinos Médio e Fundamental (AEEMF). As três disciplinas foram planejadas em conjunto por três professores, de forma articulada, sendo respeitadas particularidades e concepções de cada um. Assim, deu-se um caráter plural às disciplinas no que diz respeito à atuação dos profissionais em aula. Cada professor trabalhou tópicos previstos nos programas das disciplinas, sendo que foram reservados momentos em que os três estavam presentes simultaneamente em sala de aula nas três disciplinas (PSEAFEM - início e fim; FTEA - início e fim; AEEMF - início, meio e fim).

O momento da presença dos três professores nos momentos iniciais de cada disciplina foi reservado principalmente para apresentação da proposta e do contrato pedagógico; os momentos de meio e/ou final de curso de disciplina foram reservados principalmente para as avaliações gerais conjuntas. O processo (desenvolvimento das disciplinas) teve como foco a experiência que cada professor-discente trouxe de sua prática em sala de aula. Foram realizadas avaliações parciais, de acordo com a forma de trabalho de cada professor e devidamente inseridas no planejamento conjunto (seminários, resenhas, relatórios, mesas redondas, elaboração de mapas mentais, de mapas conceituais e/ou de diagramas V). Também foram realizadas avaliações gerais e finais, adotadas pelos três professores e planejadas em conjunto, que são descritas na sequência.

a) avaliação conjunta - PSEAFEM: envolveu a apresentação oral e escrita de proposta de unidade sobre um tema - mais abrangente; a apresentação oral e escrita de proposta de aula teórica e de aula experimental - assunto mais específico. Tais planejamentos deveriam contemplar o tema e os assuntos predefinidos, sendo que cada grupo deveria dissertar sobre eles. Para cada plano de aula, o professor-discente deveria fornecer no documento escrito e, na apresentação oral, os respectivos planos, roteiros e materiais relacionados. As atividades deveriam ser realizadas em duplas (ou trios) de professores-discentes, sendo que cada um deveria elaborar uma aula teórica e uma aula experimental. Portanto, cada plano de unidade deveria contemplar, no mínimo, quatro ou seis aulas;

b) avaliação conjunta - FTEA: envolveu a apresentação oral e escrita de proposta de aula com base nas propostas de aula - disciplina PSEAFEM. Dentre as quatro (ou seis) propostas de aula, os professores-discentes deveriam 
escolher duas (ou três) e adaptá-las para um método relacionado às teorias de aprendizagem discutidas na disciplina. Essas aulas deveriam conter enfoques filosóficos diferentes. Para cada aula, deveriam fornecer no documento escrito e na apresentação oral os respectivos planos, os roteiros e o material relacionado. Cada um dos grupos de dois alunos (ou três) (mesmos da disciplina PSEAFEM) tinha 30 minutos para a apresentação de suas propostas e mais 30 minutos para discussão com a turma e os professores. Ao final de todas as apresentações, foram dados mais 45 minutos para as considerações finais;

c) avaliação conjunta - AEEMF: os professores-discentes deveriam propor um instrumento que permitisse estabelecer um processo crítico de avaliação das atividades desenvolvidas pelos professores em suas aulas experimentais e que também seria utilizado para a avaliação das atividades desenvolvidas por eles.

Cada um dos professores desenvolveu três aulas experimentais com a turma (em três manhãs). Após essa sequência de aulas, os grupos deveriam apresentar a análise crítica das atividades, tendo por base o instrumento de avaliação elaborado, realizando um feedback do processo, até então. Na sequência, ocorreu a apresentação das atividades experimentais planejadas pelos professores-discentes (cada grupo dispunha de uma manhã ou tarde, sendo que cada membro do grupo tinha 45 minutos para desenvolver uma aula experimental). Ao final de todas as apresentações, ocorreu a avaliação e as considerações finais (em um período).

A seguir, apresentam-se as ementas, os objetivos gerais e específicos, a distribuição dos conteúdos e as atividades propostas e desenvolvidas em cada uma das disciplinas, segundo a sequência de execução no MNPEF-UEPG.

\section{Processos e Sequências de Ensino e Aprendizagem em Física no Ensino Médio (PSEAFM)}

- Ementa: esta disciplina deverá ter um caráter aplicado, ou seja, seu foco será diretamente a sala de aula, em termos do processo de ensino-aprendizagem. Por exemplo, a preparação de um tutorial a partir da identificação de dificuldades dos alunos na aprendizagem de um determinado tópico de Física Clássica ou Moderna e Contemporânea; a construção de uma sequência de ensino-aprendizagem (TLS - Teaching Learning Sequence); a elaboração de uma unidade de ensino potencialmente significativa (Ueps).

- Objetivo geral: elaborar sequências de ensino-aprendizagem com vários enfoques. 
- Objetivos específicos: observar aulas com base no processo ensino-aprendizagem; analisar o processo de ensino-aprendizagem; elaboração mapas mentais e mapas conceituais de um determinado tópico de Física Clássica ou Moderna e Contemporânea; elaborar uma sequência de ensino-aprendizagem (TLS - Teaching Learning Sequence); elaborar uma unidade de ensino potencialmente significativa (Ueps).

- Estrutura do conteúdo: apresentação da disciplina; análise de documentos oficiais norteadores do ensino de Ciências: a relação da Física e a disciplina de Ciências do ensino fundamental nos documentos federais, a relação da Física e a disciplina de Ciências do ensino fundamental nos documentos estaduais; instrumentos de apoio para o ensino de Física no ensino médio: livros, periódicos especializados, projetos de ensino de Física, material de multimeios disponíveis; desenvolvimento de uma sequência de aulas teóricas e experimentais: escolha e estudo do tema, estruturação da unidade por assuntos, elaboração de material de apoio, elaboração das estratégias de ensino, elaboração do programa da unidade, elaboração do plano de aula de cada assunto da unidade; atividades educacionais de Física Clássica ou Moderna e Contemporânea: apresentação das propostas, análise e discussão pela turma.

- Estratégias de ensino: as estratégias metodológicas empregadas serão compostas por: aulas expositivas, seminários por meio de estudo e leitura de textos e pesquisas teóricas, construção de modelos, exibição de documentários, trabalhos individuais, trabalhos coletivos, construção de mapas mentais, mapas conceituais e diagramas $\mathrm{V}$.

- Atividades propostas: elaborar o planejamento de uma unidade de ensino sobre temática preestabelecida. Cada integrante do grupo (três alunos) deverá elaborar um plano de aula teórica e um plano de aula experimental. Assim, a unidade deverá ser pensada com um número mínimo de seis aulas. Apresentação oral e escrita de proposta de unidade: sobre um tema - mais abrangente; proposta de aula - assunto mais específico (teórica); proposta de aula - assunto mais específico (experimental). Contemplar o tema e os assuntos, dissertando sobre eles. Para cada aula, fornecer, no documento escrito e na apresentação oral, os respectivos planos, roteiros e material relacionado.

- Temas propostos: em 2014: movimentos, energia, luz e som, átomos, eletromagnetismo e astronomia; em 2016 e 2017: energia em processos naturais e tecnológicos (termodinâmica); movimento em processos naturais e tecnológicos; matéria e radiação em sistemas e processos naturais e tecnológicos; 
comunicação e informação em sistemas e processos naturais e tecnológicos; eletromagnetismo em sistemas e processos naturais e tecnológicos.

\section{Fundamentos Teóricos em Ensino e Aprendizagem (FTEA)}

- Ementa: esta disciplina tem como objetivo familiarizar professores de Física em serviço com enfoques teóricos da aprendizagem e do ensino, ajudando-os na construção de um sistema de referência teórica para a sua ação docente. Apresenta noções básicas de teorias de aprendizagem e ensino como sistema de referência para análise de questões relativas ao ensino da Física nos níveis médio e fundamental; as primeiras teorias behavioristas (Watson, Guthrie e Thorndike); o behaviorismo de Skinner; o neobehaviorismo de Gagné; o cognitivismo de Piaget, Bruner, Vigotsky, Ausubel e Kelly; o humanismo de Rogers e Novak; a teoria dos modelos mentais de Johnson-Laird; a teoria dos campos conceituais de Vergnaud; as pedagogias de Freire.

- Objetivos gerais: promover a familiarização de professores de Física em serviço com noções básicas de teorias de aprendizagem e ensino como sistema de referência para sua ação docente; analisar questões relativas ao ensino da Física nos níveis médio e fundamental, de acordo com a adequada transposição dos conteúdos necessários relativos ao conhecimento de Física.

- Objetivos específicos: sistematizar as ideias essenciais das diversas teorias de aprendizagem; abordar o ensino de Física em relação às teorias de aprendizagem; confrontar ideias de teorias de aprendizagem com situações reais.

- Estrutura do conteúdo: apresentação da disciplina; investigação prévia da turma em relação às teorias de aprendizagem e ensino; principais enfoques do comportamentalismo: Watson, Guthrie, Thorndike, Skinner, Gagné; principais enfoques do cognitivismo: Piaget, Bruner, Ausubel, Johnson-Laird, Vergnaud; principais enfoques do sociointeracionismo: Vygotsky, Freire; principais enfoques do humanismo: Kelly, Rogers, Novak; noções gerais de teorias contemporâneas da aprendizagem; exemplificações: atividades educacionais no ensino básico.

- Estratégias de ensino: as estratégias metodológicas empregadas serão compostas por aulas expositivas, seminários por meio de estudo e leitura de textos e pesquisas teóricas, construção de modelos, exibição de documentários, trabalhos individuais, trabalhos coletivos, construção de mapas mentais, mapas conceituais e diagramas $\mathrm{V}$. 
- Atividades propostas: apresentação oral e escrita de proposta de aula, tendo por base as propostas de aula da disciplina PSEAFEM. Dentre as seis propostas de aula (PSEAFEM), escolher três. Para as escolhidas: adaptar para um método relacionado às teorias de aprendizagem discutidas nas disciplinas; para cada uma, dar enfoques filosóficos diferentes: Comportamentalismo, Cognitivismo e Humanismo; para cada aula, fornecer, no documento escrito e na apresentação oral, os respectivos planos, roteiros e materiais relacionados. Obs.: inserir, no plano de aula, o item - princípios metodológicos.

\section{Atividades Experimentais para 0 Ensino Médio e Fundamental (AEEMF)}

- Ementa: estruturas conceituais, metodológicas e de interação entre a teoria e a prática dos experimentos. Critérios para escolha e preparação de atividades experimentais. Ensino- aprendizagem: objetivos das atividades experimentais. Aprendizagem de conceitos, atitudes, habilidades do processo de experimentação e investigação científica. Experiências demonstrativas, didáticas, estruturadas e não estruturadas. Administração: segurança na execução da atividade experimental em sala de aula e em laboratório. Experimentação, coleta e análise de dados por meio de interfaces de hardware e recursos de software. Avaliação: perspectivas e diretrizes.

- Objetivos gerais: analisar cientificamente um dispositivo experimental; desenvolver projetos instrumentais para aulas teóricas e experimentais no ensino de Física; desenvolver material didático teórico e experimental para aulas no ensino de Física; reconhecer as potencialidades de instrumentos para aulas teóricas e experimentais no ensino de Física.

- Objetivos específicos: identificar o referencial teórico no qual se baseia o método utilizado num trabalho laboratorial; formular hipóteses sobre um fenômeno susceptível de ser observado em laboratório; conceber um procedimento experimental capaz de validar uma dada hipótese ou estabelecer relações entre variáveis; construir uma montagem laboratorial a partir de um esquema ou de uma descrição; desenvolver material didático teórico e experimental para aulas no ensino de Física; reconhecer as potencialidades de instrumentos para aulas teóricas e experimentais no ensino de Física.

- Estrutura do conteúdo: atividades experimentais para a educação básica: natureza das atividades; estruturas conceituais e metodológicas; interação entre a teoria e a prática dos experimentos; objetivos; critérios; métodos; análise de dados; avaliação de aprendizagem; abordagens de atividades experimentais para a educação básica: abordagens de demonstração; aborda- 
gens de prática laboratorial executadas pelos alunos; abordagens em clube de ciências; abordagens extraclasse.

- Estratégias de ensino: as estratégias metodológicas empregadas serão compostas por aulas expositivas, seminários por meio de estudo e leitura de textos e pesquisas teóricas, construção de modelos, exibição de documentários, trabalhos individuais, trabalhos coletivos, construção de mapas mentais, mapas conceituais e diagramas $\mathrm{V}$.

- Atividades propostas: os professores desenvolverão uma série de atividades experimentais com a turma (três manhãs). Ao final de cada período, as equipes deverão elaborar uma análise crítica das atividades realizadas: proposição de um instrumento que permita estabelecer um processo crítico das atividades desenvolvidas. Grupos de três professores-discentes (os mesmos das disciplinas anteriores). Ao final de todas as apresentações dos professores, haverá um período (manhã) de 30 minutos, por grupo, para a apresentação das análises críticas realizadas. Ao final dessas apresentações, haverá um feedback do processo, até esta etapa. Cada equipe terá uma manhã (ou) tarde para a apresentação das atividades experimentais planejadas. Nesse momento, cada membro da equipe terá 45 minutos para desenvolver uma aula experimental. Ao final, as demais equipes terão 30 minutos para avaliação (análise crítica) das aulas experimentais. Ao final de todas as apresentações, haverá um período (uma tarde) para as considerações finais.

\section{Reflexões sobre a experiência de sequência didática no MNPEF-UEPG}

Com a formação do MNPEF, pretende-se que os professores-discentes compreendam a relevância da organização de seu trabalho no espaço escolar na perspectiva da garantia da aprendizagem e do desenvolvimento humano dos estudantes da educação básica, conforme meta estabelecida no Plano Nacional de Educação (BRASIL, 2014). Destacam-se como pontos fundamentais nesta formação a leitura e a reflexão dos referenciais teóricos disponibilizados nas três disciplinas, considerando-se o objetivo de aprofundar as discussões sobre a articulação entre conhecimentos da Física e as diversas áreas relacionadas, a partir da realidade escolar.

A perspectiva de integração de conhecimentos exige que os professores ampliem suas compreensões sobre a totalidade dos componentes curriculares, na forma de disciplinas bem como de outras possibilidades de organização do conhe- 
cimento escolar. Segundo Lima et al., essa integração se dá a partir de quatro dimensões fundamentais:

a) compreensão sobre os sujeitos do Ensino Médio considerando suas experiências e suas necessidades; b) escolha de conhecimentos relevantes de modo a produzir conteúdo contextualizado nas diversas situações onde a educação no Ensino Médio é produzida; c) planejamento que propicie a explicitação das práticas de docência e que amplie a diversificação das intervenções no sentido da integração nas áreas e entre áreas; d) avaliação que permita ao estudante compreender suas aprendizagens e ao docente identificá-las para novos planejamentos (2014, p. 4).

Nessa perspectiva, propõe-se uma série de atividades de reflexão a respeito das ferramentas de planejamento na organização do trabalho pedagógico. Nessa tarefa, buscou-se propiciar aos professores-discentes bases referenciais trabalhadas de modo reflexivo, construtivo e sequencial nas três disciplinas. Para cada um dos referenciais teóricos abordados, foram propostas questões de reflexão e ação, com base em questões que conduziam a construção das propostas de planejamento por parte dos professores-discentes. A seguir, indica-se os temas abordados em cada uma das disciplinas e se estabelece uma reflexão do processo em suas particularidades na construção contínua do conhecimento.

\section{Processos e sequências de ensino e aprendizagem em Física no ensino médio (PSEAFEM)}

Esta disciplina iniciou-se com o estudo dos documentos oficiais norteadores da educação básica brasileira: a Lei no. 9.394/1996, que estabelece as Diretrizes e Bases da Educação Nacional (LDBEN) (BRASIL, 1996), a Lei oㅜ 13.005, de 25 de junho de 2014, que aprova o Plano Nacional de Educação (PNE) (BRASIL, 2014), as Diretrizes Curriculares Nacionais (DCNs) (BRASIL, 2013), as Diretrizes Curriculares da Educação Básica - Física (DCE) (PARANÁ, 2008) e a Base Nacional Comum Curricular (BNCC) (BRASIL, 2017). Esses estudos foram divididos em três seções de quatro horas-aula cada, aos sábados pela manhã. Para evitar o ensino centrado no professor e a passividade dos professores-discentes, optou-se por estratégias de ensino ativas, isto é, eles deveriam produzir conteúdo. O estudo da LDBEN (BRASIL, 1996) começou com a apresentação de um vídeo, produzido pela TV Senado e disponível no YouTube (TV SENADO, 2014), sobre a vida de Darcy Ribeiro. O vídeo tem duração aproximada de 6 minutos e tem como objetivo apresentar aos professores-discentes o personagem histórico brasileiro que inspirou a lei que dá ao sistema educacional a "necessária unidade em meio a diversidade que caracteriza o país” (BRASIL, 1996) e que é direito de todo cidadão.

Assim, sensibilizados pelo documentário, os professores-discentes assistiram a uma curta apresentação sobre as disposições encontradas na lei e a sua estru- 
tura. Com um quadro sobre todos os nove títulos, os professores-discentes foram divididos em cinco grupos de três membros e foram convidados a elaborar apresentações, na forma de fluxograma, com as principais disposições encontradas em cada título. A divisão dos conteúdos e o gerenciamento das atividades de leitura e pesquisa ficaram a cargo dos professores-discentes. Organizar e sintetizar os conteúdos da LDBEN na forma de fluxograma foi o grande desafio que eles tiveram de enfrentar, pois as apresentações deveriam conter, no máximo, duas páginas. Após uma semana de intervalo, os professores-discentes apresentaram os fluxogramas acompanhados de análise e crítica. Das doze horas-aula disponíveis, foram utilizadas oito horas-aula no estudo da LDBEN (BRASIL, 1996).

Para a semana seguinte, os professores-discentes foram instruídos a ler sobre o PNE e as DCNs, como estudo prévio para a abordagem de conteúdo seguinte, o estudo da BNCC. A estratégia utilizada foi a da webquest, buscando respostas para as seguintes perguntas: o que é o PNE? Quais são as metas propostas pelo PNE? O que são as diretrizes curriculares? Para que servem as diretrizes curriculares? Como até o ano de 2017, a BNCC era apenas uma proposta ainda a ser aprovada, os professores-discentes assistiram a uma apresentação mostrando os envolvidos na elaboração da proposta, o que ela apresenta, que ela é uma exigência da LDBEN, do PNE e das DCNs, qual a sua finalidade, quais as suas políticas decorrentes e quais as principais características das etapas de escolarização?

Nessa apresentação, foi dada ênfase ao estudo da área de Ciências da Natureza, destacando o forte caráter de investigação, de apropriação de linguagens e das relações entre ciência, tecnologia, sociedade e ambiente. A Física, como parte integrante das Ciências da Natureza, e como ela deve ser abordada nos ensinos fundamental e médio, serviu como questão central para a produção de podcasts pelos cinco grupos de professores-discentes, tirando-os novamente do papel passivo de meros expectadores de uma aula expositiva para o papel de produtores de conteúdo. Assim, foi apresentado o software livre e de código aberto Audacity ${ }^{\circledR 1}$ e a página com músicas de conteúdo livre Free Music Archive, ${ }^{2}$ como recursos para a produção dos podcasts.

O item "instrumentos de apoio para o ensino de física no ensino médio: livros; periódicos especializados; projetos de ensino de Física; material de multimeios disponíveis", da disciplina PSEAFEM, foi trabalhado como descrito a seguir. Inicialmente, foram apresentados o método de trabalho e o processo de avaliação parcial, porque se entende que é de fundamental importância que as partes, professores e professores-discentes, conheçam a sistemática de trabalho da qual irão participar efetivamente. Em seguida, a turma foi organizada em grupos, de acordo com o estabelecido no primeiro dia de aula. Com relação ao método de trabalho adotado, a 
dinâmica da aula foi focada no professor-discente, por meio de discussões, análises de materiais e realização de atividades individuais, em grupo ou em turma, promovendo, assim, a diversificação de práticas em sala de aula.

Em princípio, foram investigadas as concepções que os professores-discentes tinham sobre os assuntos pertinentes à temática central. De maneira geral, foram elaborados mapas mentais, individuais e em grupos, mapas conceituais em grupos, propostas de atividades educacionais em grupos, momentos de discussão em grupo e em turma. Todo o processo foi orientado e mediado pelo professor e quando foram dadas explicações breves sobre mapas mentais (BUZAN, 2005; MARQUES, 2008) e conceituais (MOREIRA, 2006), para que os professores-discentes pudessem elaborar um material apropriado para a investigação proposta.

Para finalizar o item, foi realizado o seminário, conforme descrito na metodologia científica (MARCONI; LAKATOS, 2001), com base nas leituras recomendadas no início da disciplina e nas atividades anteriores, propostas e realizadas nesse item. A condução do seminário contou com três professores-discentes, responsáveis pela sua dinâmica, que foram escolhidos pelos demais, a saber: o mediador da discussão, responsável pela orientação da discussão, o primeiro secretário, responsável pela documentação da discussão, elaboração da síntese e leitura final para todos os participantes, e o segundo secretário, responsável pelas inscrições, pelo controle do tempo de intervenção de cada participante e pelo apoio que fosse necessário ao mediador e primeiro secretário. Extraclasse, foi feita a elaboração da síntese do seminário, documento escrito em forma de ata, com discussão da elaboração e leitura final de todos os participantes por meio virtual, via correio eletrônico. Para esse item, foram utilizados meios didáticos diversificados, tais como lousa, álbum seriado, multimídia ou similar, celulares e notebook.

A avaliação parcial desse item foi em forma de seminário, sendo que foi exigido de cada aluno, grupo e turma a efetivação: das leituras recomendadas; da preparação de material com apontamentos de acordo com as leituras; das relações efetuadas das leituras recomendas com as atividades realizadas nas aulas anteriores ao seminário; da participação nas atividades; e do registro final em forma de ata.

Por fim, foram abordados os temas: desenvolvimento de uma sequência de aulas teóricas e experimentais: escolha e estudo do tema; estruturação da unidade por assuntos; elaboração de material de apoio; elaboração das estratégias de ensino; elaboração do programa da unidade; elaboração do plano de aula de cada assunto da unidade.

Nessa etapa, discutiu-se a importância do planejamento, apresentando-se os pressupostos conceituais, propondo-se um modelo de composição do planejamento escolar. Assim, o planejamento escolar é um marco operativo obtido a partir 
dos marcos situacional e referencial (GANDIN, 1995). Foram realizados estudos teóricos, discussões coletivas e produção de quadros-síntese e mapas conceituais (MOREIRA, 2006). Todas as tarefas realizadas envolviam o relato e a discussão por parte da turma, de modo que cada um dos professores-discentes pudesse refletir sobre a sua realidade escolar frente aos elementos teóricos apresentados.

A disciplina PSEAFEM proporcionou a elaboração de planos de unidade e planos de aulas por parte dos professores-discentes. Pode-se indicar que, no desenvolvimento da disciplina, procurou-se estabelecer paralelos de tais planejamentos com a elaboração de um produto educacional, como previsto no regulamento do programa como um dos critérios para a obtenção do título de mestre em ensino de Física.

\section{Fundamentos teóricos em ensino e aprendizagem (FTEA)}

Na disciplina FTEA, buscou-se sistematizar as ideias essenciais das diversas teorias de aprendizagem. Procurou-se, ainda, abordar o ensino de Física seguindo as teorias de aprendizagem. Foram desenvolvidas atividades individuais, em grupo e em turma, no sentido de confrontar ideias de teorias de aprendizagem com situações da realidade escolar. A investigação prévia da turma em relação às teorias de aprendizagem e ensino e os principais enfoques do comportamentalismo: Watson, Guthrie, Thorndike, Skinner e Gagné foram trabalhados como relatado a seguir.

Com a intenção de manter a uniformidade da prática docente, foram apresentados o método de trabalho e de avaliação parcial, a turma foi organizada em grupos de acordo com o estabelecido no primeiro dia de aula, o método de trabalho adotado foi de aulas com dinâmica focada no professor-discente. De maneira geral, na investigação dos conhecimentos prévios, foram feitas perguntas iniciais com repostas individuais e que, ao final dos questionamentos, foram compartilhadas, discutidas e feitas considerações em plenária. No trabalho com os enfoques do comportamentalismo, foram propostas duas atividades educacionais: a primeira relacionada à teoria de aprendizagem de Skinner e baseada na instrução programada - Física auto-instrutivo (SAAD; YAMAMURA; WATANABE, 1973) e a segunda relacionada à hierarquização de Gagné (LEFRANÇOIS, 2013; MOREIRA, 1999, 2014), na qual cada aluno resolveu um exercício de um livro didático do ensino médio, de acordo com a sua prática em sala de aula. Em plenária, um professor-discente expôs a sua resolução do problema e, em seguida, foram discutidas questões de elementos que nem sempre aparecem explícitos numa resolução de problema na lousa.

Tanto a investigação inicial quanto as duas atividades educacionais tiveram como intenção promover o ambiente para os trabalhos com a temática dos principais 
enfoques do comportamentalismo. O trabalho foi desenvolvido de forma que, em equipe e também em plenária, fossem discutidos primeiramente termos e, num segundo momento, abordagens de ensino e aprendizagem relativos à temática. Nos dois casos, seguiram-se breves leituras pertinentes à temática, com textos de Lefrançois (2013) e Moreira (1999, 2014), sendo específicas para cada grupo, isto é, diferentes termos e diferentes abordagens para cada equipe, com plenárias para apresentação e discussão. O fechamento se deu pela discussão geral e com algumas recomendações para as atividades futuras, no âmbito da disciplina e do curso de mestrado pelo professor. Novamente, foi elaborada a síntese da plenária, documento escrito em forma de ata, com discussão da elaboração e leitura final dos participantes por meio virtual, via correio eletrônico, nos mesmos moldes da disciplina PSEAFEM.

Para a abordagem da filosofia cognitivista, principais enfoques do cognitivismo, foram apresentadas as teorias de aprendizagem de Jean Piaget, Lev Vygotsky, David Ausubel, Philip Johnson-Laird e Gérard Vergnaud, na forma de slides. Mesmo utilizando uma forma bastante tradicional de apresentação do conteúdo, nesta sequência, os alunos tiveram a oportunidade de estabelecer os pontos comuns entre as teorias e as principais diferenças entre elas. Assim, em contraposição ao behaviorismo, o cognitivismo foi apresentado como uma abordagem teórica de aprendizagem que explora os processos mentais superiores. Ao final da aula, os alunos tiveram oportunidade de organizar os seus conhecimentos sobre o cognitivismo, com um relato pessoal associando o seu método de ensino praticado em sala de aula e os principais conceitos dessa filosofia.

$\mathrm{Na}$ etapa final, foram abordados os conteúdos: principais enfoques do sociointeracionismo: Vygotsky; Freire e principais enfoques do humanismo: Kelly; Rogers; Novak e noções gerais de teorias contemporâneas da aprendizagem.

De forma geral, nessa disciplina, foram abordados aspectos essenciais das teorias de aprendizagem e como podem contribuir para o planejamento do ensino de Física. Os principais textos utilizados foram os livros de Moreira (1999, 2014), Lefrançois (2013) e Illeris (2013). Como consequência, os planos-piloto de unidade e de aulas desenvolvidos na disciplina PSEAFEM foram revisitados e reelaborados, incluindo-se elementos referenciais metodológicos, tendo por base as teorias de aprendizagem.

\section{Atividades experimentais para os ensinos médio e fundamental (AEEMF)}

Nessa disciplina, inicialmente, foi apresentada pelos professores uma sequência de aulas experimentais, a fim de mostrar uma pluralidade de possibilidades de abordagem com base no marco teórico escolhido. Com essa atividade, foram discu- 
tidos os aspectos gerais sobre atividades experimentais em sala de aula e, por fim, foram norteadas ações para avaliação efetiva de aulas experimentais de acordo com o foco que se emprega a elas.

Após as atividades experimentais realizadas pelos professores, ocorreu a apresentação do episódio "Por que as estrelas brilham", do desenho animado nacional "O Show da Luna", disponível no YouTube (SHOW DA LUNA, 2017), produzido pela TV Pinguim, que serviu como organizador prévio para que os professores-discentes entendessem as principais características que devem estar presentes em uma aula experimental. "O Show da Luna" foi escolhido porque todos os episódios iniciam-se com uma criança curiosa querendo descobrir por que ocorrem certos fenômenos naturais. São companheiros de aventura da Luna o seu irmão Júpiter e um furão chamado Cláudio.

Todos os episódios fundamentam-se no exercício do método científico, embora, muitas vezes, de maneira não linear, culmina na apresentação dos resultados das pesquisas feitas por Luna, seu irmão e o pequeno furão na forma de um show, o "Show da Luna". Ao final da apresentação, os professores-discentes são levados a algumas reflexões, como: Luna é uma menina - destaca-se a participação das mulheres na ciência; Júpiter é o irmão igualmente curioso que "embarca" nas pesquisas da Luna; Cláudio é o furão que só fala quando a imaginação de Luna e Júpiter afloram; os adultos, pai e mãe da Luna e Júpiter, não são os protagonistas, mas os expectadores da apresentação final dos resultados, isto é, do "show"; o método científico está evidente nas etapas de aparecimento do problema, formulação de hipóteses, testagem/pesquisa das hipóteses, conclusão e apresentação dos resultados.

A partir dessa abordagem inicial, o texto The goal of introductory laboratories (AMERICAN ASSOCIATION OF PHYSICS TEACHERS, 2017) foi adaptado para uma apresentação de slides com o objetivo de mostrar os principais aspectos da arte da experimentação, as habilidades analíticas e experimentais a serem desenvolvidas pelos alunos da educação básica, a aprendizagem conceitual, a compreensão do conhecimento físico, o desenvolvimento de habilidades cooperativas e de resolução de problemas complexos e, por fim, a comunicação dos resultados. A síntese integradora se fez por meio de uma reinterpretação da proposta do desenho animado e das repercussões em sala de aula, principalmente, no redirecionamento das aulas experimentais em escolas de ensino fundamental e médio.

Assim, o objetivo principal foi, na verdade, levar os professores-discentes a refletir sobre as suas práticas metodológicas de ensino experimental: coloco meu aluno como protagonista da organização da pesquisa experimental? Aproveito a sua curiosidade natural para conseguir engajá-lo na aprendizagem da ciência? Ensino-o a planejar e organizar um experimento? Oportunizo aprendizagem com 
ferramentas computacionais que envolvam o tratamento estatístico de dados experimentais? Dou a oportunidade de expressão para que ele possa, de maneira organizada, expressar os seus resultados? Incentivo-o a produzir o seu próprio conhecimento?

As abordagens de atividades experimentais para a educação básica: abordagens de demonstração; abordagens de prática laboratorial executadas pelos alunos; abordagens em clube de ciências; abordagens extraclasse, na disciplina AEEMF, foram trabalhadas como indicado a seguir.

Como nas disciplinas PSEAFEM e FTEA, com a intenção de manter a uniformidade da prática docente, na AEEMF, foram apresentados os métodos de trabalho e de avaliação parcial, a turma foi organizada em grupos de acordo com o estabelecido no primeiro dia de aula, o método de trabalho adotado foi de aulas com dinâmica focada no professor-discente.

O enfoque da temática deu-se em três partes: introdução; experimentação para o ensino médio em sala de aula; e experimentação para o ensino médio em espaços não formais. Ao início da aula, foi distribuído material de anotações com roteiro que deveria ser seguido em todos os momentos, um para cada grupo; durante os momentos, foram distribuídos materiais. A temática foi trabalhada de forma a promover o intercâmbio de ideias e, a partir das práticas dos professores-discentes, foram feitas duas breves leituras: um poema de Barros (1996, p. 47) e um parágrafo da introdução de Feynman, Leighton e Sands (2008, p. 1), com discussão livre e relativa à física, respectivamente, investigação de relações entre metas de laboratório em experimentos de física ou ciências e ideias-chaves e, também, investigação de ensino de Física ou ciências em espaços não formais e ideias-chaves relacionadas.

O processo ocorreu em partes, sempre com discussão geral das considerações elencadas em relação aos assuntos em foco, em cada parte, da seguinte maneira: cada grupo teve espaço para expor e explicar o assunto; em seguida, promoveu-se a negociação de ideias de forma livre, porém organizada, para ver as ponderações feitas na discussão do assunto pelos grupos; nesses momentos, sempre foi levado em consideração o referencial teórico que foi indicado para leituras posteriores.

De maneira geral, o recurso utilizado foi material impresso: documento para a anotação da equipe com espaços específicos e papeletas impressas, ambos elaborados pelo professor, além do uso da lousa.

A avaliação foi de forma qualitativa, por meio das observações da interação entre os membros das equipes, a turma e professor, durante os momentos de discussão, e quantitativa, por meio do documento impresso, que foi preenchido durante o processo e entregue ao final da aula. 
Na etapa final de estudos teóricos da disciplina, foram abordados os seguintes temas: atividades experimentais para a educação básica: objetivos; critérios; métodos; análise de dados; avaliação da aprendizagem.

O principal elemento de discussão e reflexão foi o processo de análise da experiência. Nesse sentido, deu-se enfoque ao processo de análise que deve ser feito em função dos objetivos propostos para o experimento. Assim, sem objetivos claros, a experiência torna-se uma atividade sem significado mais profundo. Nesse estabelecimento de objetivos é que está a base de qualquer análise e, inclusive, a base da utilidade do trabalho experimental, bem como o estabelecimento de uma flexibilidade na elaboração do programa experimental, que permitirá a sua aplicação, ainda que as condições materiais não sejam ideais para sua realização. Justamente, a função da análise experimental é possibilitar o ensino experimental em quaisquer condições, cumprindo a missão que se propõe analisar. Por isso, com as práticas propostas na disciplina AEEMF, a análise das atividades experimentais tem como propósito mostrar que há possibilidade de introduzir o ensino com bases experimentais, mesmo em condições que aparentemente sejam pouco favoráveis. Essa análise, ainda, deve ter a inclusão de exigências da experiência do ponto de vista didático e material.

Como previsto no início dos trabalhos, ainda na primeira disciplina, PSEAFEM, os professores-discentes reelaboraram os planos de unidades e de aula produzidos nas disciplinas PSEAFEM e FTEA, em um processo de reflexão e amadurecimento sobre a proposta inicial. Das propostas, foram apresentadas apenas as aulas experimentais, a fim de mostrar uma pluralidade de possibilidades de abordagem com base no marco teórico escolhido. Foram discutidos os aspectos gerais sobre atividades experimentais em sala de aula e, por fim, foi realizada a avaliação da efetividade das aulas experimentais, de acordo com o foco que se se propôs para elas.

\section{Considerações finais}

Como síntese do processo construído ao logo das três disciplinas, PSEAFEM, FTEA e AEEMF, pode-se estabelecer que as atividades desenvolvidas permitiram observar a aplicação da proposta de ensino fundamentada em método, metodologias, técnicas e recursos instrucionais, que possibilitou uma análise da prática docente por parte dos professores-discentes. Além disso, as três disciplinas constituíram-se em espaço para a reflexão coletiva acerca da prática docente e da importância da participação de todos os atores do processo educativo na escola. As disciplinas permitiram estabelecer a prática da sistematização, do registro e da análise de experiências vivenciadas no espaço escolar. As reflexões individuais e co- 
letivas integraram a oportunidade de conhecimento aprofundado do espaço escolar com o reconhecimento de que peculiaridades locais podem influenciar a atividade docente, favorecendo ou dificultando a aprendizagem.

\section{Notas}

1 Audacity®. Disponível em: <https:/www.audacityteam.org/>. Acesso em: 9 abr. 2017.

2 Free Music Archive. Disponível em: <http://freemusicarchive.org/>. Acesso em: 9 abr. 2017.

\section{Referências}

AMERICAN ASSOCIATION OF PHYSICS TEACHERS. The goal of introductory laboratories. 2017. Disponível em: <https://www.aapt.org/Resources/policy/goaloflabs.cfm>. Acesso em: 5 ago. 2017.

BARROS, Manoel. Desejar ser. In: . Livro sobre nada. 3. ed. Rio de janeiro: Record, 1996. p. 35-64.

BRASIL. Lei no 9.394, de 20 de dezembro de 1996. Brasília, DF, 1996. Disponível em: <http:// www.planalto.gov.br/ccivil_03/Leis/L9394.htm>. Acesso em: 3 mar. 2017.

Lei $\mathrm{n}^{\mathrm{o}}$ 11.502, de julho de 2007. Brasília, DF, 2007. Disponível em: <http://www.planalto. gov.br/ccivil_03/_ato2007-2010/2007/lei//11502.htm>. Acesso em: 12 dez. 2017.

Ministério da Educação. Secretaria de Educação Básica. Secretaria de Educação Continuada, Alfabetização, Diversidade e Inclusão. Secretaria de Educação Profissional e Tecnológica. Conselho Nacional da Educação. Câmara Nacional de Educação Básica. Diretrizes Curriculares Nacionais da Educação Básica. Brasília: MEC, SEB, Dicei, 2013. Disponível em: <http://portal. mec.gov.br/index.php?option=com_docman\&view=download\&alias=13448-diretrizes-curiculares-nacionais-2013-pdf\&Itemid=30192> . Acesso em: $12 \mathrm{dez} .2017$.

Lei no 13.005, de 25 de junho de 2014. Diário Oficial da República Federativa do Brasil, Brasília, DF, 26 jun. 2014. Edição Extra, p. 1. Disponível em: <http://www.planalto.gov.br/CCIVIL_03/_Ato2011-2014/2014/Lei/L13005.htm>. Acesso em: 12 dez. 2017

Base Nacional Comum Curricular. Brasília, DF, 2017. Disponível em: <http://basenacionalcomum.mec.gov.br/>. Acesso em: $12 \mathrm{dez} .2017$

BUZAN, Tony. Mapas mentais e sua colaboração: um sistema definitivo de pensamento que transforma sua vida. São Paulo: Cultrix, 2005.

BRASIL. Ministério da Educação. O sistema nacional de formação docente. Brasília, DF, 2017. Disponível em: <http://portal.mec.gov.br/rede-nacional-de-formacao-de-professores/sitema-nacional-de-formacao-de-professores>. Acesso em: $12 \mathrm{dez} .2017$.

COORDENAÇÃO DE APERFEIÇOAMENTO DE PESSOAL DE NÍVEL SUPERIOR. Cursos avaliados e reconhecidos. 2018. Disponível em: <https://sucupira.capes.gov.br/sucupira/public/ consultas/coleta/programa/quantitativos/quantitativoAreaAvaliacao.jsf;jsessionid=IpC19tcuSC VdbQWNHKsjYjWE.sucupira-213>. Acesso em: 12 jan. 2018. 
Formação de professores da educação básica. 2017a. Disponível em: <http://www.capes. gov.br/educacao-basica>. Acesso em: 12 dez. 2017.

Plano Nacional de Pós-Graduação (PNPG) 2011-2020. Comissão Especial de Acompanhamento do PNPG 2011-2020. Relatório final 2016: Sumário Executivo. Brasília: Capes, 2017b. Disponível em: <http://capes.gov.br/images/stories/download/relatorios/231117-Relatorio-PNPG-Final-2016-CS.pdf>. Acesso em: 12 dez. 2017.

FEYNMAN, Richard P.; LEIGHTON, Robert B.; SANDS, Matthew. Átomos em movimento. In: . Lições de Física de Feynman. Porto Alegre: Bookman, 2008. p. 1-10.

GANDIN, Danilo. A prática do planejamento participativo: na educação e em outras instituições, grupos e movimentos dos campos cultural, social, político, religioso e governamental. Petrópolis, RJ: Vozes, 1995.

GATTI, Bernadete A.; BARRETTO, Elba S. de S. Professores no Brasil: impasses e desafios. Brasília: UNESCO, 2009. Disponível em: <http://www.unesco.org/new/fileadmin/MULTIMEDIA/ FIELD/Brasilia/pdf/professores_brasil_resumo_executivo_2009.pdf>. Acesso em: 12 dez. 2017.

ILLERIS, Knud (Org.). Teorias contemporâneas da aprendizagem. Porto Alegre: Penso, 2013.

LEFRANÇOIS, Guy R. Teorias da aprendizagem. São Paulo: Cengage Learning, 2013.

LIMA, Erisevelton S. et al. Formação de professores do ensino médio, Etapa II - Caderno I: organização do trabalho pedagógico no ensino médio. Curitiba: UFPR/Setor de Educação, 2014. Disponível em: <http://observatoriodajuventude.ufmg.br/pacto-mg/images/Cadernos_2_Etapa/ Caderno-1-E2-FINAL.pdf>. Acesso em: 15 ago. 2014.

MARCONI, Marina A.; LAKATOS, Eva M. Metodologia do trabalho científico. 6. ed. São Paulo: Atlas, 2001.

MARQUES, António M. de M. Utilização pedagógica de mapas mentais e de mapas conceptuais. 2008. 153 f. Dissertação (Mestrado em Expressão Gráfica, Cor e Imagem) - Programa de Pós-Graduação em Expressão Gráfica, Cor e Imagem, Universidade Aberta, Lisboa, 2008. Disponível em: <https://repositorioaberto.uab.pt/handle/10400.2/1259>. Acesso em: 15 ago. 2014.

MOREIRA, Marco Antonio. A teoria da aprendizagem significativa e sua implementação em sala de aula. Brasília: UnB, 2006.

Teorias de aprendizagem. São Paulo: EPU, 1999.

Teorias de aprendizagem. 2. ed. ampl. São Paulo: EPU, 2014.

PARANÁ. Diretrizes Curriculares da Educação Básica - Física. 2008. Disponível em: <http:// www.educadores.diaadia.pr.gov.br/arquivos/File/diretrizes/dce_fis.pdf>. Acesso em: 12 dez. 2017

SOCIEDADE BRASILEIRA DE FÍSICA. Programa Nacional de Mestrado Profissional em Ensino de Física (MNPEF): apresentação. 2018. Disponível em: <http://www1.fisica.org.br/mnpef/?q =apresenta\%C3\%A7\%C3\%A3o>. Acesso em: 12 dez. 2017.

SAAD, Fuad Daher; YAMAMURA, Paulo; WATANABE, Kazuo (Org.). Física auto-instrutivo FIA2. São Paulo: Saraiva, 1973. v. 2. 
SHOW DA LUNA. O Show da Luna! Por que as estrelas piscam? - Episódio Completo. 2017. Disponível em: <https://www.youtube.com/watch?v=JLbrlrOIfFo\&t=528s >. Acesso em: 25 set. 2017.

TV SENADO. Grandes personagens - Darcy Ribeiro (1922-1997) - Bloco 1. 2017. Disponível em: <https://www.youtube.com/watch?time_continue=6\&v=f36qmmlfumY>. Acesso em: 3 mar. 2017.

ORGANIZAÇÃO DAS NAÇÕES UNIDAS PARA A EDUCAÇÃO, A CIÊNCIA E A CULTURA. Qualificação e capacitação de professores. 2017. Disponível em: <http://www.unesco.org/new/pt/ brasilia/education/educational-governance/teacher-education-and-training/>. Acesso em: $12 \mathrm{dez}$. 2017.

UNIVERSIDADE DE CAMPINAS. Fórum: A Universidade Pública e o Ensino de Ciências: investigando a experiência dos Mestrados Profissionais para a Qualificação dos Professores. Campinas: Unicamp, 2015. Disponível em: <http://www.gr.unicamp.br/penses/forum-mestrado-profissional/>. Acesso em: 12 dez. 2017. 